\title{
THE LOS ANGELES MEETING
}

\author{
By BERT BOYD, D.D.S., Los Angeles, California
}

$\mathrm{T}$ HE 64th annual meeting of the American Dental Association became a matter of history on the afternoon of Friday, July 21, 1922, at the Ambassador Hotel, Los Angeles, California.

Of intense interest to all sections of the United States, this meeting marked an epoch in the existence of the profession of dentistry on the Pacific coast; particularly in California and more particularly in southern California, because of its being also the celebration of the twentyfifth anniversary of the latter organization.

What was the great motive which prompted the members of the Southern California Dental Association and the other coast dental societies to strive for the honor of acting as host to such a wonderful body of men and women as are found in the American Dental Association?

Only to see this portion of our country, of which we may justly be proud? Most emphatically no. The presence of the leaders of any great organization, in a given place, for a week, with the bulk of the time given to the dissemination and acquisition of knowledge appertaining directly to the life and progress of that organization is a stimulus to be coveted.

This, then, was the impelling incentive in the hearts of the members of these several associations and made them more than willing to labor hard and long to obtain and provide for such an inspirational gathering.

Was a lethargic state of the dental profession on the Pacific slope a reason for wishing a national meeting in our midst?

On the contrary, the personnel of the profession in this district is composed of those in whom there lives a constant and sincere desire to keep a little more than abreast of the times and to accumulate and dispense ideas which are really helpful in the progress of dentistry. A perusal of the recent program will, we are certain, verify this statement.

To successfully stage a national meeting two thousand or more miles from the centers of dental activity is no small undertaking, but it takes a greater obstacle than this to "wet blanket" the spirit of a genuine Californian.

That the California spirit of "co-operation" and "boost" is not confined to real-estators alone, but permeates all lines of activity, dentistry included, was evidenced before and during the convention.

A book could be written regarding the months of laborious effort put forth by those of the local committees, but to what purpose. The knowledge that the 1922 convention was a decided success in every particular is sufficient and amply repays all who were responsible.

What reasons are had for feeling that the convention was a success? It was held in a wonderfully progressive city, in a spacious and beautiful hotel and grounds, ideally situated, and the registered attendance was nearly five thousand.

The program was a splendid one and well presented. The intense and sus- 


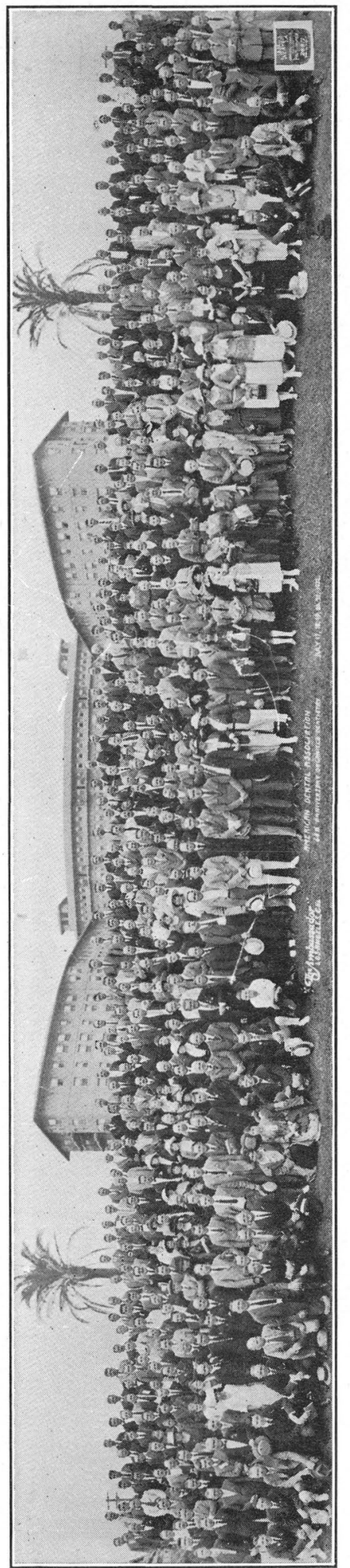

tained interest, particularly in the work of the several sections, was really remarkable and probably exceeded at no other national convention. The rooms in which these sessions were held were crowded continually.

The group clinics deserve special mention as they spoke volumes for the months and months of effort put forth in their preparation.

The opening general session on Tuesday morning, July 18, in the theater in the hotel, with every seat taken and hundreds standing in the foyer, gave assurance of a successful meeting. The addresses of welcome; the responses and the president's address, were impressive and ably given.

One of the pleasant features and a happy surprise, was the presentation to President Hartzell of an orange wood gavel, suitably mounted and engraved in gold and silver and given by the Local Arrangements Committee and the Southern California Dental Association.

The second general session on Tuesday evening, at the Trinity Auditorium, down town, was a health meeting and open to the public. The attendance was most gratifying, the audience most attentive and appreciative and the addresses by Dr. Thos. B. Hartzell, Miss Evelyn Schmidt and Dr. Guy S. Millberry were above par.

One of the outstanding features of the convention was the Public Health Exhibit under a great tent, erected over the double tennis court. Nothing quite like this has ever been presented and proved of inestimable value educationally, both to the layman and dentist. Undoubtedly much more prominence will be given to these demonstrations at future conventions.

We were told months before the convention, that the manufacturers' exhibit would be about the finest ever. If there is any doubt that it was, ask any exhibitor who occupied space on the floor of that beautiful dining room and get his answer. Ask him concerning the volume of business he transacted and see him 
smile. We have not a word to retract from the statement made at the beginning of this paragraph.

If we are to judge by the expressions coming from those who visited the convention, and were recipients of the hospitality and entertainment offered by the committee and the dentists of southern California, the convention was a decided success from the entertainment standpoint.

Was the convention a financial success? Read the report which is to be sent to the trustees of the American Dental Association soon and be your own judge. There will be no deficit you may be assured. But above all, the most convincing reason we have for believing in the success of the meeting is the feeling among the dentists of our own jurisdiction.

It has resulted in the addition of over two hundred new members in the past year and aroused an enthusiasm which will be felt for years to come.

Everywhere, members of the profession are striving to become more profi- cient servants of the public, and we know that a large percentage of our own will benefit immeasurably from the visit of the national body to Los Angeles in 1922 and be given a stronger desire to "perform dentistry that will add ten years to human life."

"Prevent," "preserve" and "progress" have a newer and larger meaning and in the degree in which we are able to accomplish these admonitions, will the measure of our future success be.

All Hail and God Speed to the American Dental Association.

Southern California is more than pleased to have had the American Dental Association as a guest and trusts that this great honor may again be ours at some future time.

The Local Arrangements Committee esteems it a great honor to have been connected with such a large undertaking as making provision for an annual meeting and is grateful for the privilege of at least having tried, with the assistance of the profession of the Pacific Coast, to make the 1922 convention, a successful one. 